OPEN ACCESS

Edited by:

Yuji Morita,

Aichi Gakuin University, Japan

Reviewed by:

Miguel Cacho Teixeira,

University of Lisbon, Portugal

Takeo Usui,

University of Tsukuba, Japan John Golin,

The Catholic University of America,

USA

*Correspondence:

Dominique Sanglard

dominique.sanglard@chuv.ch;

Rajendra Prasad

rprasad@ggn.amity.edu;

rp47jnu@gmail.com

Specialty section:

This article was submitted to Antimicrobials, Resistance and

Chemotherapy,

a section of the journal

Frontiers in Microbiology

Received: 02 January 2016

Accepted: 16 February 2016

Published: 03 March 2016

Citation:

Banerjee A, Khande/wal NK, Sanglard D and Prasad R (2016) A New Endogenous Overexpression System of Multidrug Transporters of

Candida albicans Suitable for Structural and Functional Studies.

Front. Microbiol. 7:261

doi: 10.3389/fmicb.2016.00261

\section{A New Endogenous Overexpression System of Multidrug Transporters of Candida albicans Suitable for Structural and Functional Studies}

\author{
Atanu Banerjee ${ }^{1}$, Nitesh K. Khandelwal ${ }^{1}$, Dominique Sanglard ${ }^{2 *}$ and Rajendra Prasad ${ }^{1,3 *}$ \\ ${ }^{1}$ Membrane Biology Laboratory, School of Life Sciences, Jawaharlal Nehru University, New Delhi, India, ${ }^{2}$ Institute of \\ Microbiology, University of Lausanne and University Hospital Center, Lausanne, Switzerland, ${ }^{3}$ Amity Institute of Integrative \\ Sciences and Health and Amity Institute of Biotechnology, Amity University Haryana, Gurgaon, India
}

Fungal pathogens have a robust array of multidrug transporters which aid in active expulsion of drugs and xenobiotics to help them evade toxic effects of drugs. Thus, these transporters impose a major impediment to effective chemotherapy. Although

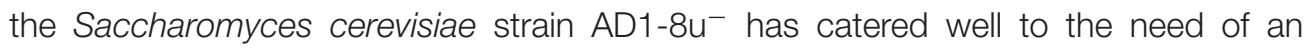
overexpression system to study drug transport by multidrug transporters of Candida albicans, artifacts associated with a heterologous system could not be excluded. To avoid the issue, we exploited a azole-resistant clinical isolate of C. albicans to develop a new system devoid of three major multidrug transporters (Cdr1p, Cdr2p, and Mdr1p) for the overexpression of multidrug transporters under native hyperactive CDR1 promoter due to gain of function (GOF) mutation in TAC1. The study deals with overexpression and functional characterization of representatives of two major classes of multidrug transporters, Cdr1p and Mdr1p, to prove the functionality of this newly developed endogenous expression system. Expression of native Cdr1 and Mdr1 protein in C. albicans cells was confirmed by confocal microscopy and immunodetection and resulted in increased resistance to the putative substrates as compared to control. The system was further validated by overexpressing a few key mutant variants of Cdr1p and Mdr1p. Together, our data confirms the utility of new endogenous overexpression system which is devoid of artifactual factors as most suited for functional characterization of multidrug transporter proteins of $C$. albicans.

Keywords: Candida albicans, multidrug transporters, endogenous overexpression system, Cdr1p, Mdr1p, TAC1 GOF

\section{INTRODUCTION}

C. albicans, an otherwise commensal of the human microbiome, can become causative agent of superficial as well as life-threatening systemic infections (Staib et al., 2000). Prolonged use of antifungals, primarily azoles, has led to the emergence of Multidrug resistance (MDR). Although MDR is a multi-factorial response, the overexpression of membrane pumps such as ABC (ATPbinding Cassette transporters) and MFS (Major-Facilitator Superfamily) transporters are the prime actors in contributing to the development of tolerance to drugs (White, 1997; Rogers and Barker, 2003). 
Heterologous overexpression of MDR pump proteins of C. albicans in Saccharomyces cerevisiae has been widely used as a novel tool for the structure-function analyses of these transporters. Such studies unpinned crucial molecular details of drug efflux, protein trafficking and transport cycle (Lamping et al., 2007; Pasrija et al., 2007; Rawal et al., 2013; Shah et al., 2015a,b). Furthermore, this system also provided novel insights regarding array of substrates recognized by these transporters (Puri et al., 2010) and critical amino acids involved in the substrate and inhibitor recognition (Saini et al., 2005; Pasrija et al., 2007; Niimi et al., 2012; Rawal et al., 2013; Nim et al., 2014). Together, the afore-mentioned applications of the heterologous system has helped in the development of therapeutic inhibitors and modulators of efflux pumps (Hayama et al., 2012; Maurya et al., 2013).

In spite of their insightful contributions, artifactual concerns associated with a heterologous background could not be neglected. Differences pertaining to the membrane components, primarily lipids could influence the insertion and proper association of the foreign transporters within the membrane compartment and thus might have an impact on the structural as well as functional properties of these proteins (Opekarova and Tanner, 2003). Moreover, the alternative codon usage of C. albicans requires mutational corrections of some codons when specific C. albicans genes need to be expressed in S. cerevisiae (Santos and Tuite, 1995).

To circumvent artifactual effects of a heterologous system and also to avoid the need of codon corrections, we have developed here an endogenous model system for the overexpression of clinically relevant multidrug transporters of C. albicans. For this, we used an azole-resistant clinical isolate of $C$. albicans where genes encoding major drug transporters CDR1, CDR2, and MDR1 were deleted. This strain, although deleted of its major MDR attributes, still contains a gain of function (GOF) mutation in TAC1 transcription factor which is responsible for a constitutive overexpression of CDR1 (Znaidi et al., 2007). A GFP tagged variant of Cdr1p was generated and integrated at its native chromosomal locus. It was observed that the overexpressed protein was properly localized to the plasma membrane and could confer drug resistance to the strain. The study confirms that this overexpression system is not only suitable for the expression of $C D R 1$ but equally suitable for non-ABC transporter genes such as MDR1.

\section{MATERIALS AND METHODS}

\section{Bacterial and Yeast Strains}

Yeast strains used in the study are listed in Table 1. Plasmids were maintained in E. coli Dh5 $\alpha$ strain cultured in Leuria Bertani medium (HiMedia Laboratories, Mumbai, India) to which ampicillin (Amresco, Solon, USA) was added at a final concentration of $0.1 \mathrm{mg} / \mathrm{ml}$. The yeast strains were cultured in either YEPD broth or on YEPD agar plates. YEPD broth was procured from HiMedia Laboratories, Mumbai, India. For selection of yeast transformants after integration, SD-Ura ${ }^{-}$drop out medium with $2 \%$ agar was used. SD-Ura ${ }^{-}$drop out medium comprised of $0.67 \%$ YNB medium without amino acids (Difco,
TABLE 1 | List of yeast strains used in the study.

\begin{tabular}{|c|c|c|c|}
\hline Strain & Genotype/Description & Parent strain & $\begin{array}{l}\text { Source/ } \\
\text { Reference }\end{array}$ \\
\hline STY31 & $\begin{array}{l}\text { cdr2A } \Delta:: \text { FRT/cdr2B } \Delta:: \text { FRT } \\
c d r 1 \mathrm{~A} \Delta:: \mathrm{FRT} / c d r 1 \mathrm{~B} \Delta:: \mathrm{FRT}\end{array}$ & 5674 & $\begin{array}{l}\text { Tsao et al., } \\
2009\end{array}$ \\
\hline DSY4680 & $\begin{array}{l}\text { cdr2A } \Delta:: \text { FRT/cdr2B } \Delta:: F R T \\
\text { cdr1A } \Delta:: F R T / c d r 1 B \Delta:: F R T \\
\text { ura3 } \Delta:: F R T / u r a 3 \Delta:: F R T\end{array}$ & STY31 & This study \\
\hline DSY4684 & $\begin{array}{l}\text { cdr2A } \Delta:: \text { FRT/cdr2B } \Delta:: \text { FRT } \\
\text { cdr1A } \Delta:: F R T / c d r 1 \mathrm{~B} \Delta:: \mathrm{FRT} \\
\text { ura3 } \Delta:: \text { FRT/ura3 } \Delta:: \mathrm{FRT} \\
\text { mdr1 } \Delta:: \text { hisG/mdr1 } \Delta:: \text { hisG }\end{array}$ & DSY4680 & This study \\
\hline DSY4687-5 & $\begin{array}{l}\text { cdr2A } \Delta:: \text { FRT/cdr2B } \Delta:: \text { FRT } \\
\text { cdr1A } \Delta:: F R T:: C D R 1- \\
\text { GFP::URA3 /cdr1B } \Delta:: F R T \\
\text { ura3 } \Delta:: F R T / u r a 3 \Delta:: F R T \\
\text { mdr1 } \Delta:: \text { hisG/mdr1 } \Delta:: \text { hisG }\end{array}$ & DSY4684 & This study \\
\hline ANY-L529A & $\begin{array}{l}\text { cdr2A } \Delta:: \text { FRT/cdr2B } \Delta:: F R T \\
\text { cdr1A } \Delta:: \text { FRT::CDR1 } 1529 A \\
\text {-GFP::URA3 / } \\
\text { cdr1B } \Delta:: \text { FRT } \\
\text { ura3 } \Delta:: \text { FRT/ura3 } \Delta:: F R T / \\
\text { mdr1 } \Delta:: \text { hisG/ } \\
\text { mdr1 } \Delta:: \text { hisG }\end{array}$ & DSY4687-5 & This study \\
\hline ANY-V532A & $\begin{array}{l}\text { cdr2A } \Delta:: F R T / c d r 2 B \Delta:: F R T \\
\text { cdr1A } \Delta:: F R T:: C D R 1 \text { V532A } \\
\text {-GFP::URA3 / } \\
\text { cdr1B } \Delta:: F R T \\
\text { ura3 } \Delta:: F R T / u r a 3 \Delta:: F R T / \\
\text { mdr1 } \Delta:: \text { hisG/ } \\
\text { mdr1 } \Delta:: \text { hisG }\end{array}$ & DSY4687-5 & This study \\
\hline ANY-C1294A & $\begin{array}{l}\text { cdr2A } \Delta:: F R T / c d r 2 B \Delta:: F R T \\
\text { cdr1A } \Delta:: F R T:: C D R 1 \text { C1294A } \\
\text {-GFP::URA3 / } \\
\text { cdr1B } \Delta:: F R T \\
\text { ura3 } \Delta:: F R T / u r a 3 \Delta:: F R T / \\
\text { mdr1 } \Delta:: \text { hisG/ } \\
\text { mdr1 } \Delta:: \text { hisG }\end{array}$ & DSY4687-5 & This study \\
\hline ANY-MDR1-GFP & $\begin{array}{l}\text { cdr2A } \Delta:: \text { FRT/cdr2B } \Delta:: \text { FRT } \\
\text { cdr1A } \Delta:: F R T:: M D R 1- \\
\text { GFP::URA3)/cdr1B } \Delta:: \text { FRT } \\
\text { ura3 } \Delta:: F R T / u r a 3 \Delta:: F R T \\
\text { mdr1 } \Delta:: \text { hisG/mdr1 } \Delta:: \text { hisG }\end{array}$ & DSY4684 & This study \\
\hline ANY-W248A & $\begin{array}{l}\text { cdr2A } \Delta:: F R T / c d r 2 B \Delta:: F R T \\
\text { cdr1A } \Delta:: F R T:: M D R 1 \text { W248A_ } \\
\text { GFP::URA3 /cdr1B } \Delta:: F R T \\
\text { ura3 } \Delta:: \text { FRT/ura3 } \Delta:: F R T \\
\text { mdr1 } \Delta:: \text { hisG/mdr1 } \Delta:: \text { hisG }\end{array}$ & ANY-MDR1-GFP & This study \\
\hline
\end{tabular}

Detroit, MI), $0.2 \% \mathrm{Ura}^{-}$dropout mix and $2 \%$ glucose (FisherScientific, Mumbai, India).

\section{Materials}

Itraconazole (ITC), Clotrimazole (CTR), Ketoconazole (KTZ), Miconazole (MCZ) and Voriconazole (VOR), Anisomycin 
(ANI), Rhodamine 6G (R6G), 4-nitroquinoline 1-oxide (NQO), Adenosine triphosphate (ATP), Oligomycin (OM), DL-Dithiothreitol (DTT), Sorbitol, Phenylmethanesulfonyl fluoride (PMSF), p-Tosyl-L-lysine chloromethyl ketone (TLCK), and Tosyl phenylalanyl chloromethyl ketone (TPCK) were procured from Sigma Chemical Co. (St. Louis, MO). Protease inhibitors leupeptin, aprotinin, Pepstatin were obtained from G-biosciences, MO, USA). Fluconazole (FLC) was a generous gift from Ranbaxy Laboratories, India. Oligonucleotides were procured from Sigma Genosys, India and are listed in Table S2. Anti-GFP monoclonal antibody was purchased from Santa Cruz Biotechnology Inc. (Texas, USA). All other routine chemicals were purchased from Fisher-scientific, Mumbai, India.

\section{Plasmid Constructions}

The homologous expression system was constructed based on Clp10 (Murad et al., 2000). The CDR1 terminator (CDR1ter) (starting $21 \mathrm{nt}$ downstream of the CDR1 stop codon) was first cloned as a 519 bp NotI-SacI fragment into Clp10 to obtain pDS1859 (Table S1). The NotI-SacI fragment CDR1ter was obtained by PCR using C. albicans SC5314 DNA as template with primers CDR1ter_SacI and CDR1Ter_NotI. Next, pDS1859 was used to insert a modified CDR1 promoter $(-1222 \mathrm{bp}$ with respect to first ATG codon) in which a natural SpeI site was destroyed. This was accomplished by a two-step fusion PCR using a first fragment obtained with primers CDR1-Apa and SpeKO3 and a second fragment obtained with primers CDR1-SpeI and SpeKO5. The two purified PCR fragments were sewed by PCR using external primers CDR1-Apa and CDR1-SpeI. The obtained fragment was cloned in pDS1859 using ApaI and SpeI restriction sites to result in pDS1866. Next, the $S$. cerevisiae PDR5 terminator was inserted as a SpeI-NheI fragment from pPSCDR1-GFP into pDS1866 to result in pDS1869. Finally the CDR1-GFP fusion from pPSCDR1-GFP was cloned as a SpeI fragment into pDS1869 to result in pDS1874.

For cloning of MDR1-GFP, the MDR1-GFP fusion from pPSMDR1-GFP was obtained by SpeI digestion. The fragment was next cloned in pDS1874 to replace CDR1-GFP, thus resulting in pAN-MDR1. The BglII site present in MDR1 cloned in pANMDR1 was removed by site directed mutagenesis.

\section{Yeast Strain Constructions}

The C. albicans strain STY31 (a kind gift from M. Raymond, Montreal) that lacks $C D R 1$ and CDR2 (Tsao et al., 2009) was used as a starting strain for the deletion of $M D R 1$. First, $U R A 3$ alleles were inactivated sequentially using pSFSU1 (Coste et al., 2006) in STY31 to obtain DSY4680 after sequential URA3 inactivation and recycling of the SAT1 dominant marker. DSY4680 was used to inactivate both MDR1 alleles with pDS287 as described (Sanglard et al., 1996). The resulting strain lacking CDR1, CDR2, and MDR1 was named DSY4684. This strain contains the TAC1 GOF N972D (Znaidi et al., 2007; Tsao et al., 2009). CDR1-GFP expression could be obtained in this strain by transformation with pDS1874 digested by BglII to facilitate integration in the CDR1 promoter. MDR1-GFP expression was obtained in DSY4684 by transformation with pAN-MDR1 digested by BglII to facilitate integration in the CDR 1 promoter.

\section{Site-Directed Mutagenesis}

Site-directed mutagenesis was performed by using Quick-Change site directed mutagenesis kit (Agilent Technologies, USA). The mutations were incorporated in pDS1874 and pAN-MDR1 plasmids according to the manufacturer's instructions and the nucleotide changes were confirmed by sequencing. Confirmed plasmid clones were used for transformation of DSY4684 using electroporation after linearization with BglII as described previously (Puri et al., 2011).

\section{Drug Susceptibility Assays}

The susceptibilities of the different yeast strains to different drugs were tested using broth microdilution and serial dilution spot assays as described previously (Shah et al., 2015b).

\section{Agar Drug Diffusion Assay}

Overnight grown cultures were diluted to an $\mathrm{OD}_{600}$ of 0.01 in YEPD agar and poured onto petri plate. Whatman paper filter discs containing the xenobiotics were placed on top of the YEPD agar plate and incubated for $48 \mathrm{~h}$ at $30^{\circ} \mathrm{C}$. Amount of xenobiotics used are mentioned in the figure legends. For the chemosensitization assay, FLC at $1 / 4 \mathrm{MIC}_{\mathrm{FLC}}$ was added to the YEPD agar containing $10^{5}$ cells and the inhibitor containing disc was placed on to the plate.

\section{Immunodetection of GFP Tagged Proteins}

Plasma membrane fractions used for immunodetection of GFP tagged proteins were prepared as described previously (Shukla et al., 2003) with minor modifications. Here, cells used for preparation for PM fractions were harvested after $8 \mathrm{~h}$ of growth. 50 micrograms of total PM proteins were used for immunodetection with HRP-labeled anti-GFP antibody at 1:5000 dilution. Protein bands were detected by BIO-RAD ChemiDoc XRS+ system following reaction with Clarity Western ECL blotting substrate (Bio-Rad).

\section{Immunodetection of Cdr1}

C. albicans total protein extracts were prepared as described (Coste et al., 2007). Same protein quantites were loaded for gel eletrophoresis and Cdr1 immunodection was performed as earlier described by chemiluminescence (ECL kit, Amersham, Bioscience) using polyclonal rabbit anti-Cdr1 antibody and an anti-rabbit-HRP labeled secondary antibody. Chemiluminescence was recorded with a ImageQuant LAS 4000 mini CCD camera (GE Healthcare Bio-Sciences).

\section{Fluorescence and Confocal Microscopy}

Cells were harvested at the requisite time points from a secondary culture, washed and viewed under Nickon Ti90 fluorescence microscope to visualize the GFP-tagged protein. For Confocal microscopy, $8 \mathrm{~h}$ grown cells were harvested and imaged using Olympus FluoView ${ }^{\mathrm{TM}}$ FV1000 laser confocal microscope (PA, USA) or Nickon Eclipse Ti E laser confocal microscope with $100 \mathrm{X}$ oil immersion objective lens.

\section{Substrate Transport Assays}

R6G efflux of the strains was determined as described previously (Shah et al., 2015b) with minor modifications. Briefly, overnight 
grown cultures were used to set an OD of 0.4 in $15 \mathrm{ml}$ of YEPD medium. The cultures were then grown for $8 \mathrm{~h}$. Cells were harvested, washed and resuspended in $1.5 \mathrm{ml}$ Phosphate buffered saline (PBS) to make a final OD of 10 . The cell suspension was then grown in the presence of $\mathrm{R} 6 \mathrm{G}$ at $10 \mu \mathrm{M}$ final concentration for $2 \mathrm{~h}$. Cells were then harvested, washed and resuspended in $1.5 \mathrm{ml} \mathrm{PBS}$ containing $2 \%$ glucose. After $45 \mathrm{~min}$, cells were pelleted and $1 \mathrm{ml}$ of the supernatant was used to measure the absorbance at $530 \mathrm{~nm}$. For NR accumulation, $8 \mathrm{~h}$ grown cultures were used to set $0.2 \mathrm{OD}$ in $1 \mathrm{ml}$ of PBS containing $2 \%$ glucose. The suspension was incubated with $7 \mu \mathrm{M}$ final concentration of NR. After $45 \mathrm{~min}$, the cells were harvested, washed with PBS and used and NR accumulation was monitored by flow cytometry using a FACSort flow cytometer (Becton-Dickinson Immunocytometry Systems, San Jose, CA). CellQuest software (Becton-Dickinson Immunocytometry Systems, San Jose, CA) was used for data analysis. For $\left[{ }^{3} \mathrm{H}\right]$ FLC (specific activity 2.8 $\mathrm{Ci} / \mathrm{mmol}$ ) accumulation assay, log phase cells were harvested, washed with PBS (Phosphate buffered saline, $\mathrm{pH}$ 7.4) and finally resuspended as $5 \%$ cell suspension. After de-energization at $30^{\circ} \mathrm{C}$ for $2 \mathrm{~h}, 0.25 \mathrm{ml}$ of $5 \%$ cell suspension (in PBS with $2 \%$ glucose) was incubated with $100 \mathrm{nM}$ final concentration of $\left[{ }^{3} \mathrm{H}\right]$ FLC. A $100 \mu \mathrm{l}$ aliquot was taken after $60 \mathrm{~min}$ of incubation at $30^{\circ} \mathrm{C}$ filtered through a $0.45 \mu \mathrm{m}$ cellulose nitrate filter using millipore manifold filtration assembly and washed twice with PBS. The filter discs were dried under a lamp and then immersed in liquid scintillation cocktail mixture (Cocktail O, SRL, India) to measure the accumulated radioactivity using liquid scintillation counter (Tri-Carb 2900TR Liquid Scintillation Analyzer; Packard).

\section{Oligomycin-Sensitive ATPase Assay}

ATPase activity of the strains was monitored by the oligomycinsensitive release of inorganic phosphate as described previously (Shah et al., 2015b). Briefly, $10 \mu \mathrm{g}$ total PM protein was used to determine the ATPase activity in an in vitro assay. $5 \mathrm{mM}$ ATP was used in the reaction mixture which was terminated after $30 \mathrm{~min}$ of incubation at $30^{\circ} \mathrm{C}$ by addition of $1 \mathrm{ml}$ of stop solution which contained $0.5 \%$ SDS, $0.5 \%$ ammonium molybdate and $2 \% \mathrm{H}_{2} \mathrm{SO}_{4} .10 \mu \mathrm{l}$ of $10 \%$ ascorbic acid was added to the solution and further incubated for $30 \mathrm{~min}$ for development of color. Absorbance of the solution was measured at $880 \mathrm{~nm}$ to assess the $\mathrm{P}_{\mathrm{i}}$ release.

\section{Statistical Analyses}

Data is represented as mean $\pm \mathrm{SD}$. The statistical analyses were performed using Student's T-Test (http://www.studentsttest.
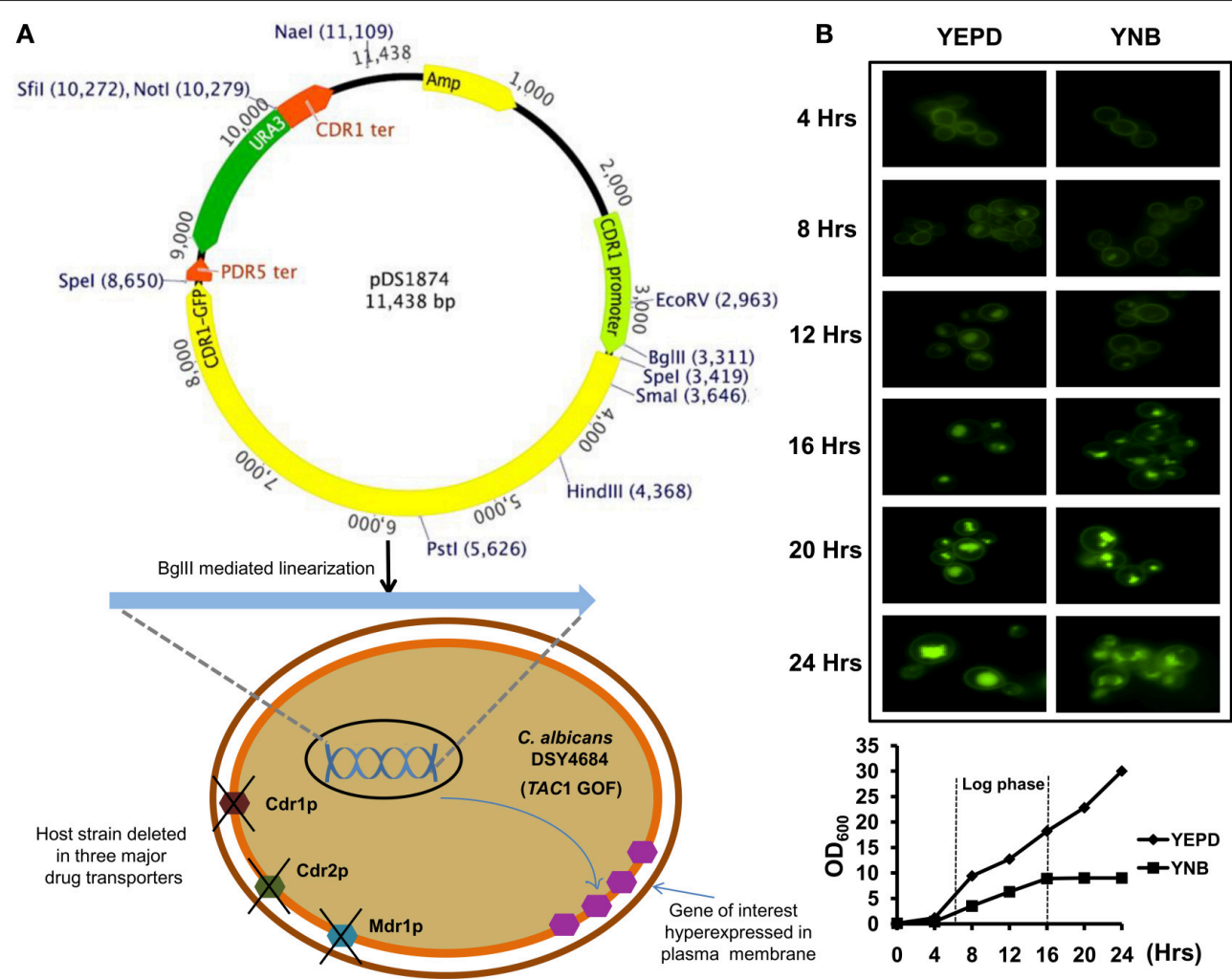

FIGURE 1 | (A) Schematic representation of the C. albicans transporter overexpression system. The system contains the promoter and terminator regions of CDR1 and a URA3 selection marker. The Spel cloning site in the plasmid can be used to insert the gene of interest. A S. cerevisiae PDR5 terminator is situated downstream of the Spel site. The plasmid can be linearized by Bglll digestion and integrated into the host strain DSY4684 which is devoid of three major MDR pumps of C. albicans (CDR1, CDR2, and MDR1). The host strain also has a GOF mutation in the TAC1 transcription factor as a result of which the cloned ORF is overexpressed under the native CDR1 promoter. (B) Time course fluorescence microscopy of DSY4687-5 strain (overexpressing Cdr1-GFP) grown in YEPD and YNB medium. Lower panel shows growth curve of the strain in the two mentioned medium at the time points used for microscopic analyses. 
$\mathrm{com} /)$. Differences were considered statistically significant when $p<0.05$ (* signifies $p<0.05$, ${ }^{* *}$ signifies $p \leq 0.01$ and ${ }^{* *}$ signifies $p \leq 0.001)$.

\section{RESULTS}

\section{Expression of Cdr1-GFP in a MDR Depleted Strain of C. albicans}

An AR isolate with a GOF mutation in TAC1 was further derivatized by deleting its major MDR pump candidates, Cdrlp, Cdr2p, and Mdr1p as well as URA3 for selection. This strain was designated as DSY4684. The CDR1 gene with a C-terminal GFP tag was introduced at the native chromosomal locus in DSY4684 by homologous recombination using URA3 as the selection marker. The integration of the CDR1-GFP chimeric construct was performed by single (BglII) digestion of pDS1874. Resulting strain was designated as DSY4687-5 (Figure 1A) and (Figure S1). Fluorescence microscopy at different growth time points revealed that Cdr1-GFP was overexpressed and correctly trafficked to the plasma membrane (PM) of DSY4687-5 (Figure 1B). Notably, the fluorescent intensity of Cdr1-GFP was the highest at 4 hours of growth and declined subsequently with time. A significant amount of fluorescence was observed within the vacuoles after 12 hours indicating that the overexpressed protein was being targeted to the vacuole for degradation. This expression trend was common in both defined (YNB) and enriched medium (YEPD). At 8 hours of growth, a considerable amount of the protein was still visible within the PM which was confirmed by confocal and immunoblot analyses of the PM fractions with an anti-GFP antibody (Figure 2A). Since the cellular yields were sufficient for functional analyses, all the subsequent studies were performed at this growth time point.

\section{Overexpressed Cdr1-GFP is Functional}

We evaluated the drug susceptibilities of DSY4687-5 and DSY4684 strains to assess the substrate transport ability of the overexpressed Cdr1-GFP. MIC $_{80}$ values for the above mentioned strains against the four well known Cdr1p substrates including Fluconazole (FLC), Ketoconazole (KTZ), Miconazole (MCZ), and Rhodamine 6G (R6G) confirmed that these drugs were efficiently effluxed by the overexpressed protein (Figure 2B). Interestingly, overexpression of Cdr1p increased the resistance of DSY4684 to FLC and MCZ by more than 50 - and 100-fold, respectively, whereas the fold change in resistance to $\mathrm{KTZ}$ and $\mathrm{R} 6 \mathrm{G}$ was 30 and 2 -fold, respectively. Agar drug-diffusion assays were employed to validate $\mathrm{MIC}_{80}$ results, which also confirmed the functionality of overexpressed Cdr1-GFP in DSY4684. It was evident from the difference in zone-of-inhibition between the tested strains
A

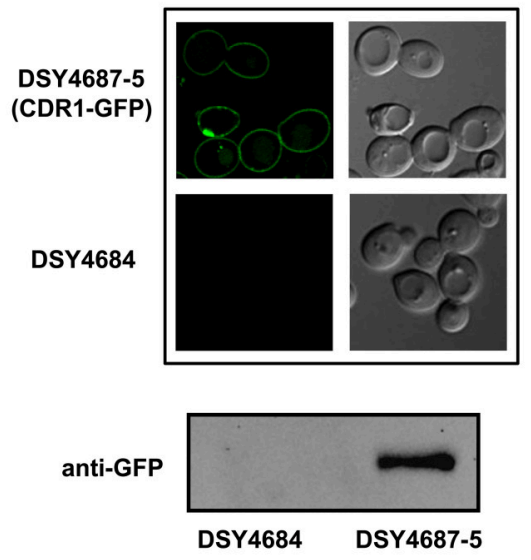

B Susceptibility to drugs $\left(\mathrm{MIC}_{80} ; \mu \mathrm{g} / \mathrm{ml}\right)$

\begin{tabular}{ccccc}
\hline Strain & FLC & KTZ & MCZ & R6G \\
DSY4684 & 1 & $<0.002$ & $<0.002$ & 8 \\
$\begin{array}{c}\text { DSY4687-5 } \\
\text { (CDR1-GFP) }\end{array}$ & 64 & 0.0625 & 0.25 & 16 \\
\hline
\end{tabular}

C

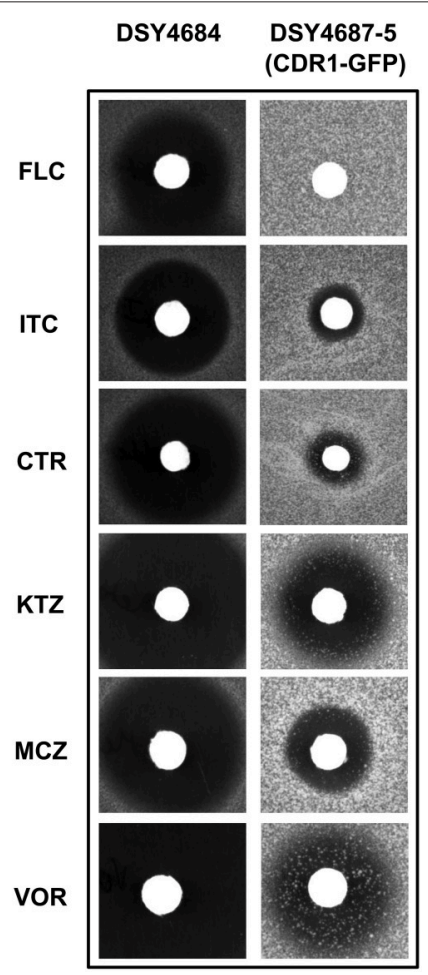

FIGURE 2 | (A) Confocal microscopy images of DSY4684 and DSY4687-5 strains (Upper panel) and immunoblot analyses of the PM fractions (50 $\mu \mathrm{g}$ total protein) with anti-GFP monoclonal antibody (Lower panel). (B) MIC 80 values of DSY4684 and DSY4687-5 cells for Fluconzole (FLC), Ketoconazole (KTZ), Miconazole (MCZ) and Rhodamine 6G (R6G). (C) Agar drug-diffusion assays of DSY4684 and DSY4687-5 cells. Susceptibility to the following azoles were tested: Fluconazole (FLC; 10 $\mu \mathrm{g}$ ), Itraconazole (ITC; $1 \mu \mathrm{g}$ ), Clotrimazole (CTR; $0.5 \mu \mathrm{g}$ ), Ketoconazole (KTZ; $0.2 \mu \mathrm{g})$, Miconazole (MCZ; $0.2 \mu \mathrm{g})$ and Voriconazole (VOR; $1 \mu \mathrm{g})$. 
that Cdr1-GFP could recognize and efflux its substrates (Figure 2C).

\section{Phenotypic Analysis of Selected Mutants of Overexpressed Cdr1p in C. albicans}

In order to further validate the newly designed endogenous expression system, we subjected the Cdr1-GFP to site directed mutational analyses. For this, we selected three residues, L529, V532, and C1294 which were earlier shown to be crucial for the efflux of substrates of Cdrlp (Rawal et al., 2013). All the three mutant variants (L529A, V532A, and C1294A) overexpressed in $S$. cerevisiae rendered cells hypersusceptible to all the tested drugs. Substrate binding/transport and molecular modeling predicted that the three residues including L529, V532, and C1294 are part of the drug binding pocket (Rawal et al., 2013). Figure 3A highlights the positions of these residues within the transmembrane helices (TMHs). For instance, L529 and V532 are part of the TMH1 whereas C1294 is located within TMH9. Considering their importance, we recreated the alanine variants of these critical residues (L529A, V532A, and C1294A) and integrated them to native chromosomal location in DSY4684. The resulting strains were designated as ANYL529A, ANY-V532A, and ANY-C1294A, respectively. Confocal microscopy and immunoblot analyses of the PM fractions with an anti-GFP antibody confirmed that all the mutant variants of Cdr1-GFP were targeted to the cell surface. However, the $\mathrm{Cdr} 1^{\mathrm{V} 532 \mathrm{~A}}$ variant was expressed at lower levels when compared to the wild type Cdr1 (DSY4687-5) and the other two variants (Figures 3B,C).

Serial dilution and liquid drug susceptibility assays were performed to assess the ability of the mutant variants to confer drug resistance. Expectedly, the results confirmed that the strains ANY-L529A and ANY-V532A were hypersusceptible to all the tested drugs corresponding to the results earlier observed in the overexpressing $S$. cerevisiae strain $\mathrm{AD} 1-8 \mathrm{u}^{-}$. Interestingly, the Cdr1 ${ }^{\text {C1294A }}$ variant showed only marginal susceptibility to R6G and remained resistant to other tested drugs (Figures 4A,B).

R6G efflux, Nile red (NR) and $\left[{ }^{3} \mathrm{H}\right]$ FLC accumulation assays were performed with the WT and the constructed mutant variants to assess whether the enhanced drug susceptibility of the mutants coincided with the defect in substrate transport. Flow cytometry which was employed to measure the NR accumulation revealed lower accumulation of the fluorescent substrate in WT cells when compared to DSY4684. All three mutant strains, ANYL529A, ANY-V532A, and ANY-C1294A, which were susceptible to drug(s), displayed intermediate levels of accumulation of NR (Figure 5A). R6G, another well-known fluorescent substrate of Cdr1p, was also used to monitor the efflux potential of the mutant variants. In accordance with the susceptibility profile for R6G, all the mutants showed a defect in transport of this fluorescent substrate (Figure 5B). The $\left[{ }^{3} \mathrm{H}\right]$ FLC accumulation assay corroborated the susceptibility profile of the mutants on FLC. While ANY-L529A, ANY-V532A showed a statistically significant defect in FLC transport, ANY-C1294A transport profile was unchanged as compared to WT. Together, the

\section{A}

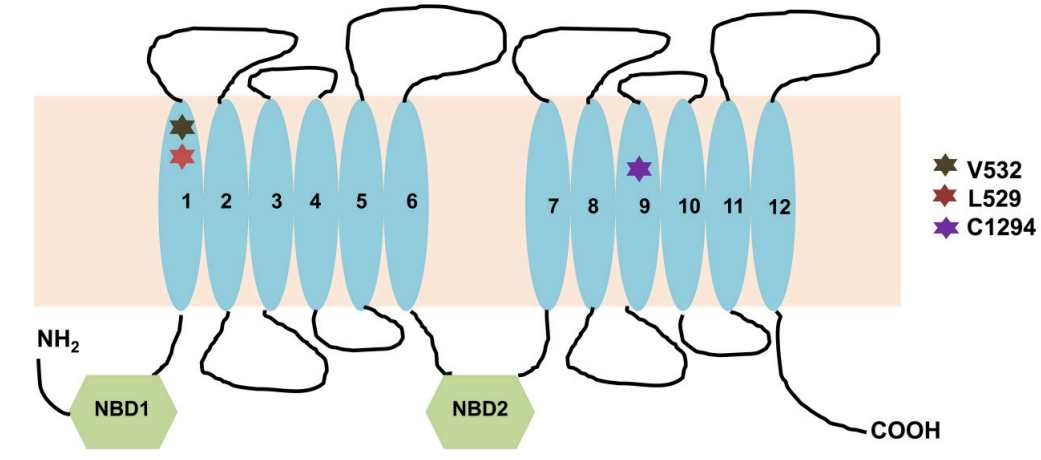

B

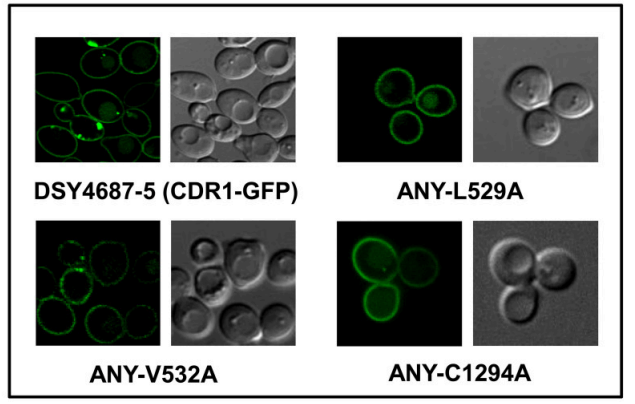

C

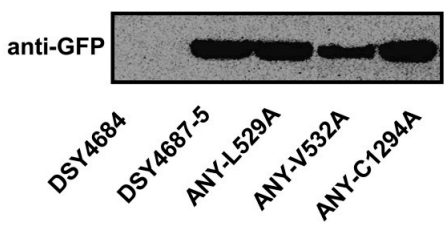

FIGURE 3 | (A) Schematic diagram of the topology of Cdr1p with highlighted amino acids selected for replacement by alanine. (B) Confocal analyses of DSY4687-5 and the three constructed mutant variant strains, ANY-L529A, ANY-V532A, and ANY-C1294A. (C) Western analyses of the PM fractions (50 $\mu \mathrm{g}$ total protein) of the strains with anti-GFP monoclonal antibody. 


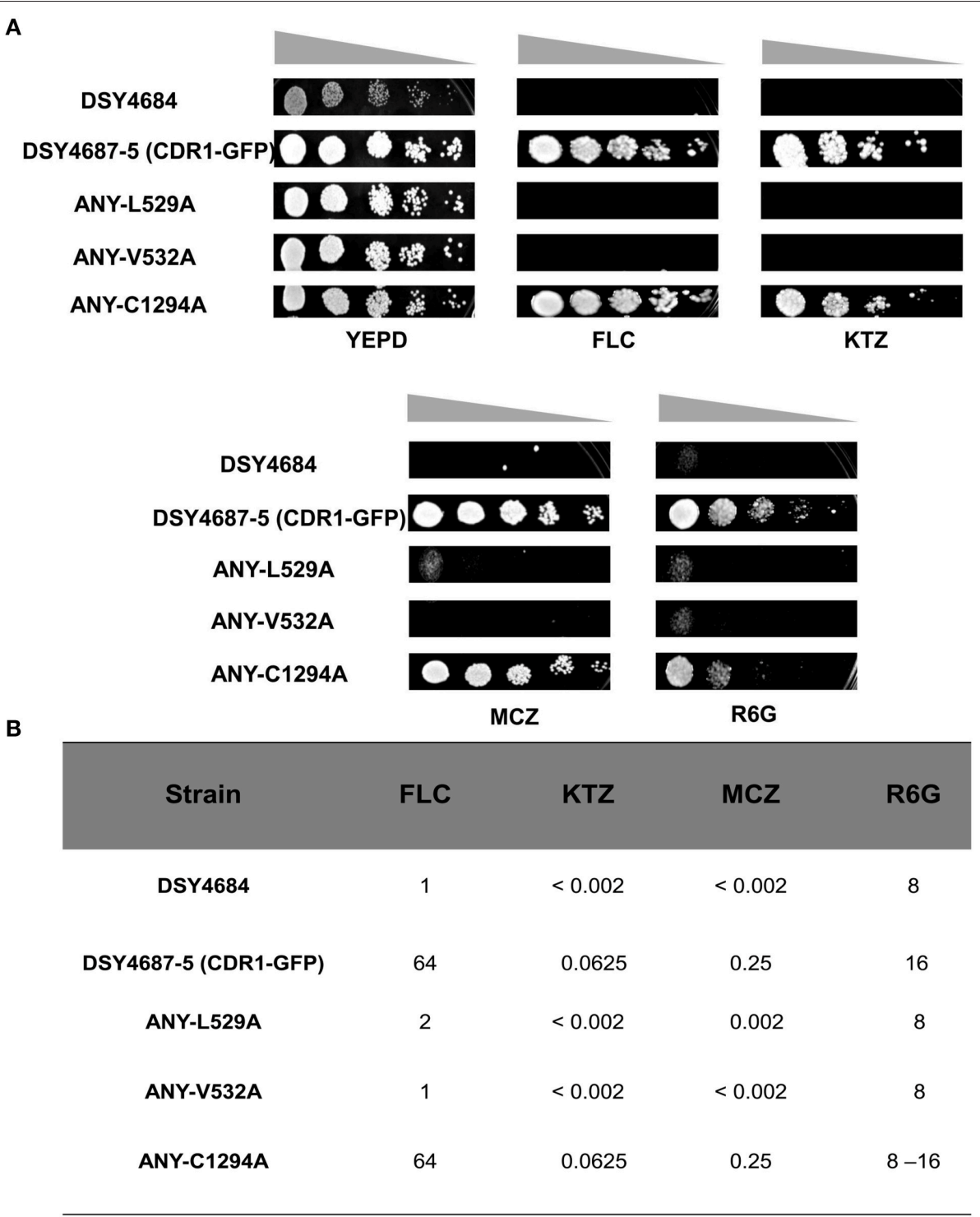

FIGURE 4 | (A) Drug resistance profiles of DSY4684, DSY4687-5 and the mutant variants determined by serial dilution spot assays. For the assay, following drugs were used: FLC $(8 \mu \mathrm{g} / \mathrm{ml})$, KTZ $(0.04 \mu \mathrm{g} / \mathrm{ml})$, MCZ $(0.04 \mu \mathrm{g} / \mathrm{ml})$, R6G (8 $\mu \mathrm{g} / \mathrm{ml})$. (B) MIC 80 values of DSY4687-5 and its mutant variants for FLC, KTC, MCZ, and R6G.

transport assays suggested that defect in the transport abilities of mutant variants of Cdr1p coincided with their antifungal susceptibilities. In spite of the fact that C1294A mutant was only partially resistant to R6G, it displayed decreased transport similar to that of the other two mutants. The oligomycin sensitive ATPase activity of the PM fractions of WT and mutant strains were checked to address whether the introduced mutations could affect the ATP catalysis cycle that could also impact substrates accumulation levels. Although ANY-L529A and ANY-V532A had statistically significant lower ATPase activities, this decrease (both strains retained over 65\% activity of WT levels, Figure 6) is not considered as significant for altering substrate transport. This is also supported by the case of the ANY-C1294A variant which retained resistance to azoles and was only partially susceptible to R6G, even if exhibiting low ATPase activity (50\% activity as compared to WT, Figure 6). Thus, any major role of low ATPase activity for the observed phenotypes could be excluded. Of note, the extensive kinetic analysis has revealed that the three investigated Cdr1p mutants were defective in substrate binding and not in ATP binding and catalysis when expressed in S. cerevisiae (Rawal et al., 2013).

\section{FK520 Chemosensitizes Cdr1p Overexpressing C. albicans Cells to Fluconazole}

We tested the ability of a calceneurin inhibitor FK520 to chemosensitize DSY4687-5 cells to FLC. Agar drug diffusion 

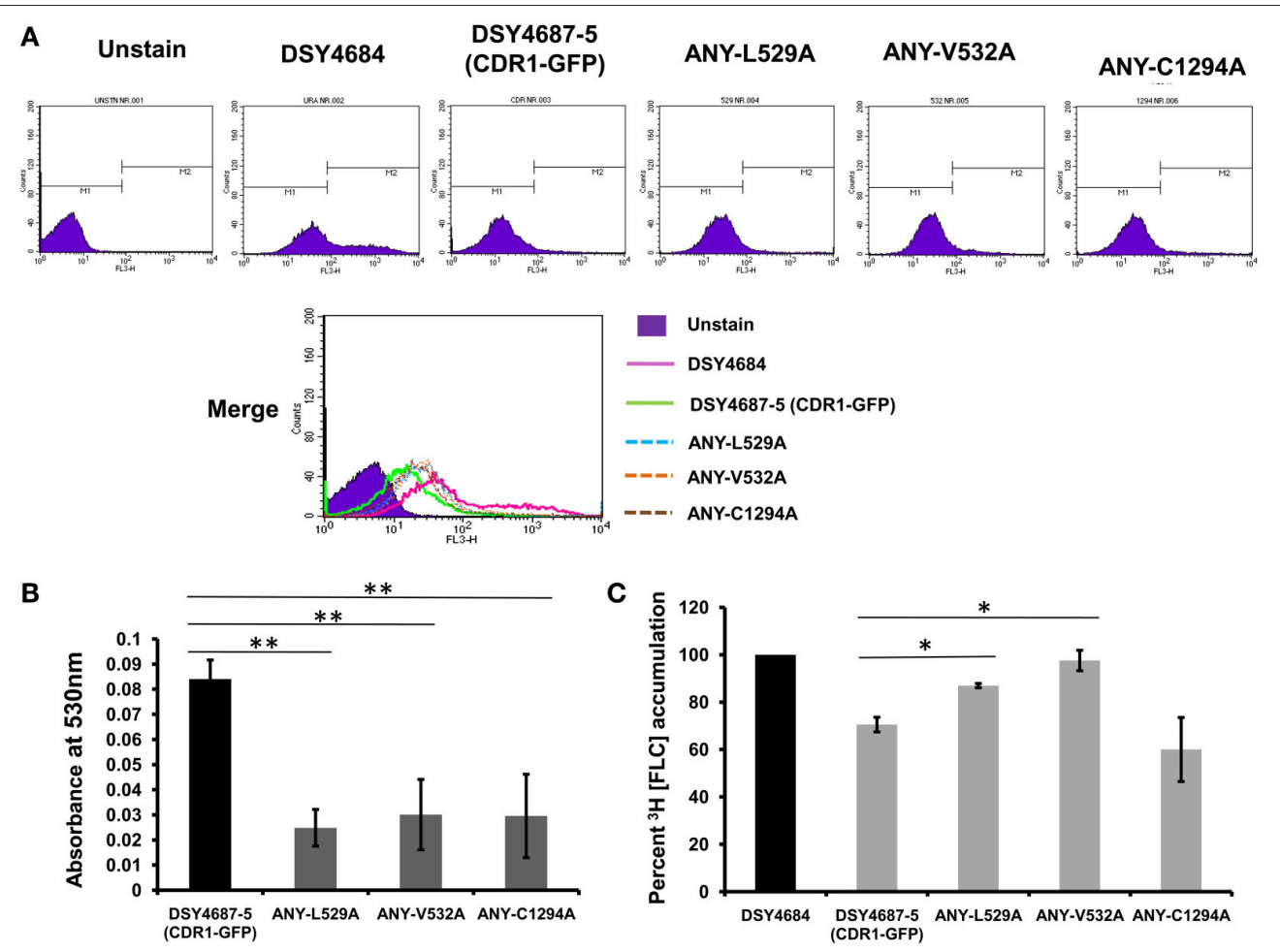

FIGURE 5 | Substrate transport assays of DSY4684, DSY4687-5 and the mutants. (A) NR accumulation in cells overexpressing Cdr1-GFP and the mutant variants as determined by Flow cytometry analyses using FL3 filter (B) R6G efflux in cells overexpressing Cdr1-GFP and the mutant variants. Assay was performed as described in the experimental section. The host DSY4684 values were subtracted from each reading. (C) $\left[{ }^{3} \mathrm{H}\right]$ FLC accumulation in cells overexpressing Cdr1-GFP and the mutant variants with respect to DSY4684 (value kept at $100 \%$ ). ${ }^{*} p<0.05 ;{ }^{* *} p \leq 0.01$.

assay was utilized for this particular investigation. In order to exclude any growth interference as a result of toxic effects of the inhibitor itself, the assay was also carried out in the absence of FLC. Despite that there was a minor reduction in growth of the cells when exposed to only $1 / 4 \mathrm{MIC}_{\mathrm{FLC}}$, it was observed that FK520 significantly enhanced the growth inhibition potential of FLC in the Cdrlp overexpressing system (Figure 7).

\section{MFS Transporter Mdr1 Could be Functionally Expressed in DSY4684}

We explored the newly developed overexpression system for the structure- function analyses of non-ABC membrane transporters. For this, we cloned the C. albicans MFS multidrug transporter protein $M D R 1$ with a GFP tag in pDS1874.After elimination of a BglII site present in $M D R 1$, the expression plasmid was linearized by BglII and introduced in CDR1 promoter of DSY4684. The resultant strain was designated ANY-MDR1-GFP. Confocal microscopy and immunoblot analyses confirmed the proper localization of Mdr1p to the PM (Figures 8A,B). Agar drug diffusion assay showed that overexpressed Mdr1-GFP was fully functional and could transport the three tested drug substrates [FLC, Nitroquinolineoxide (NQO) and Anisomycin (ANS)] (Figure 8C). To further validate functionality, we also introduced a mutation at one crucial position (W248A) into Mdr1-GFP and overexpressed this mutant variant in similar background and the resulting strain was designated as ANY-W248A. Serial dilution assays on agar medium containing drugs revealed that this W248A mutant variant was susceptible to all tested drugs, as was observed earlier when overexpressed in a S. cerevisiae system (Pasrija et al., 2007; Figure 8D).

\section{DISCUSSION}

It is evident from the current literature that membrane efflux pumps pose a major impediment to effective antifungal therapy (White et al., 1998; Sanglard and Odds, 2002). Under such a scenario, it is quite imperative to have a thorough understanding of the structure and function of multidrug transporters. Thus, one of the foremost requirements is the need of an overexpression system which could drive constitutive and functional expression of the drug transporter proteins with minimum artifactual effects. Such a system is not only expected to facilitate the functional characterization of these transporters, but would also provide a platform for screening of their drug susbstrates and inhibitors/modulators.

During the past several years, $S$. cerevisiae has been successfully exploited as an overexpression system which provided useful insight into the structure-function aspects and substrate/inhibitor screening of drug transporter proteins of $C$. 
albicans. Despite such applications of overexpressing system of $S$. cerevisiae by several laboratories, concerns were raised pertaining to the functionality of $C$. albicans proteins in a heterologous background. This concern is even more relevant

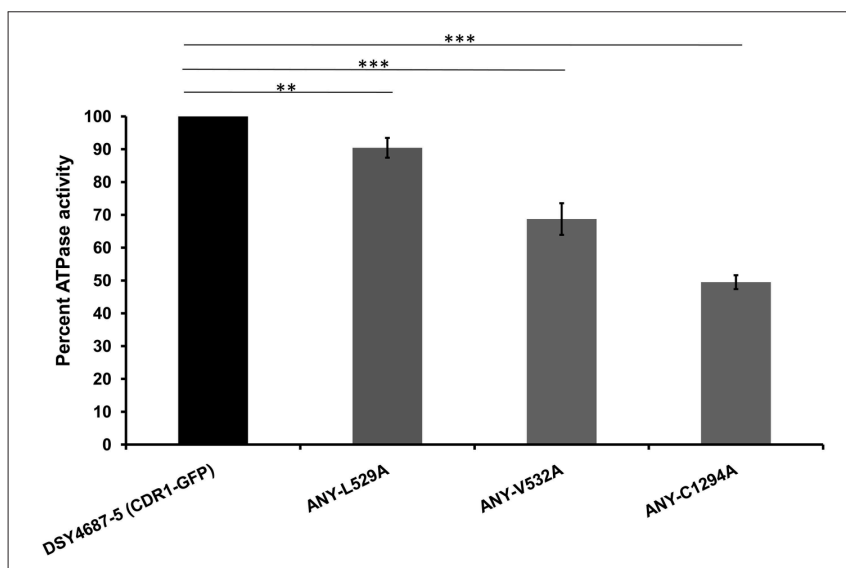

FIGURE 6 | Oligomycin-sensitive ATPase activity of DSY4687-5 and its mutant forms monitored by $P_{i}$ released from the $P M$ fractions of the strains. Complete method described in the experimental section. Value of the WT strain (DSY4687-5) was kept at 100\%. Background oligomycin-sensitive ATPase of the host has been subtracted from all the respective values. ATPase activities for the host (DSY4684) and WT (DSY4687-5) ranged between 15 and $20 \mathrm{nmoles} \mathrm{Pi} / \mathrm{mg}$ of total PM protein/min and $60-75 \mathrm{nmoles} \mathrm{Pi} / \mathrm{mg}$ of total PM protein/min, respectively. ${ }^{* \star} p \leq 0.01 ;{ }^{* * *} p \leq 0.001$. if one considers that the homologs of MDR transporters of C. albicans and S. cerevisiae follow different regulatory circuits for their expression. Additionally, since all drug efflux pumps are PM localized, the subtle differences in membrane composition and architecture between the two yeasts could also have crucial implications in protein insertion, integrity and function. Lipid environment for instance, impacts drug transport and ATPase functions of P-glycoprotein (P-gp) (Saeki et al., 1991; Urbatsch and Senior, 1995; Sharom, 1997). In particular, the phase state of lipid bilayer is crucial for ATPase activity of P-gp (Sharom, 1997). The membrane component, cholesterol, is also well known to affect ATPase activity and function of P-gp (Rothnie et al., 2001). The yeast membrane ergosterol, a substitute of cholesterol, can also affect the efflux functions of Pdr5p (Kaur and Bachhawat, 1999). Our group has earlier observed that lipid species such as ergosterol and sphingolipids are crucial for proper insertion of Cdrlp to PM and substrate efflux (Krishnamurthy, 1999; Pasrija et al., 2008). Notwithstanding, several studies related to $\mathrm{Cdr} 1 \mathrm{p} / \mathrm{Cd} 2 \mathrm{p}$ and Mdr1p of C. albicans have provided very useful information related to their structure and function in a heterologous expression system, even if expression of heterologous proteins in $S$. cerevisiae can be associated with potential artifacts.

This study addressed these concerns by developing an endogenous overexpression system for $C$. albicans multidrug transporter proteins. We took advantage of an AR isolate containing a TAC1 GOF mutation (Znaidi et al., 2007; Tsao et al., 2009). This strain possesses intrinsic high expression capacity of

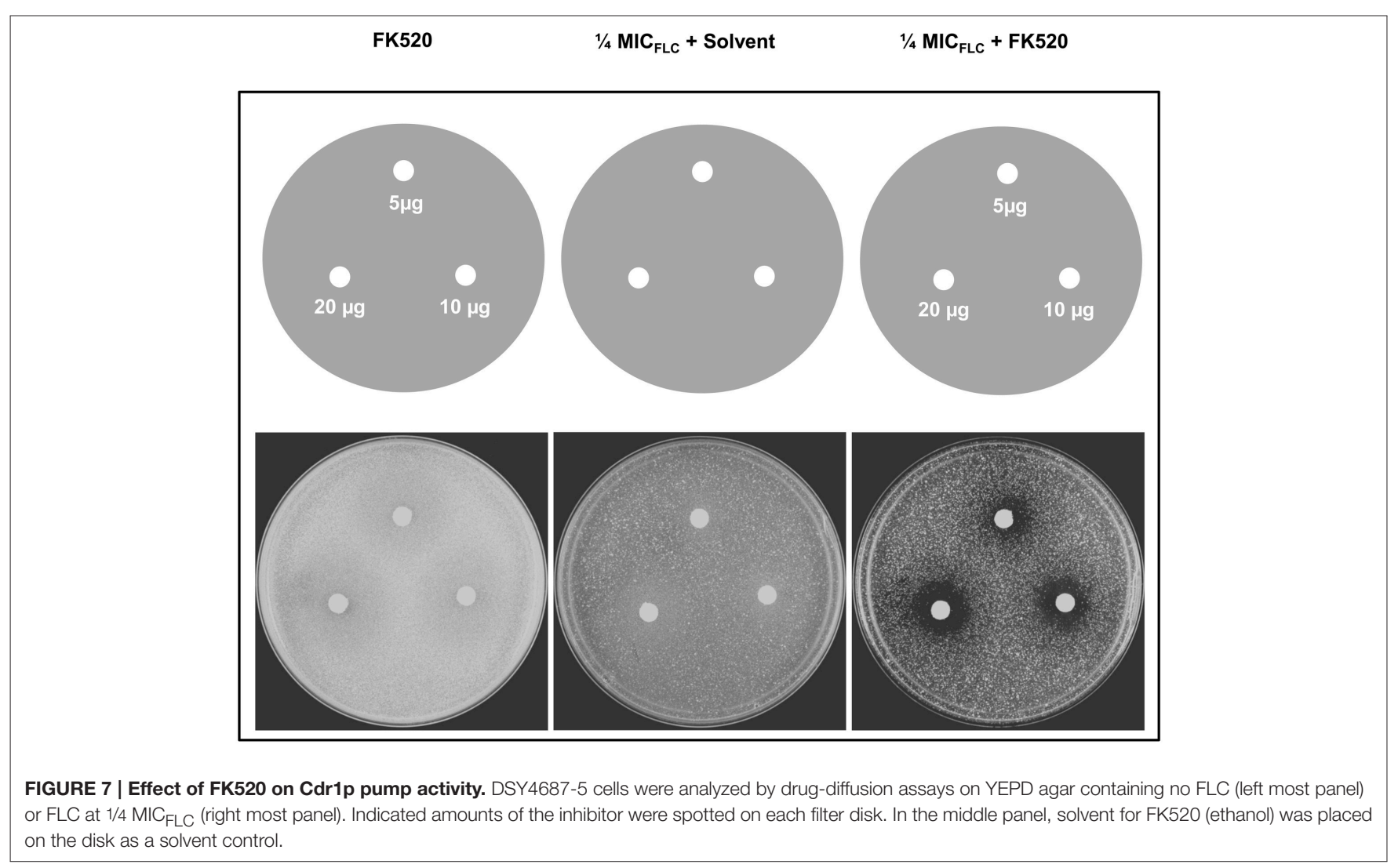




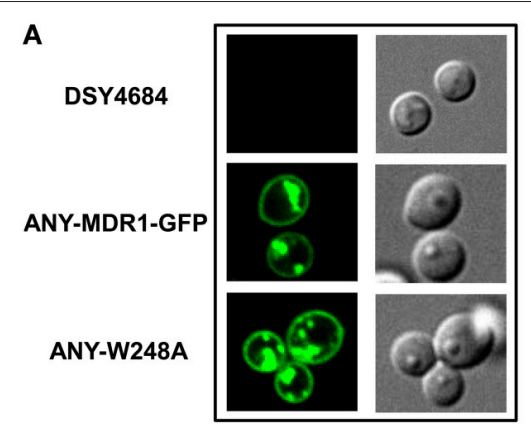

B

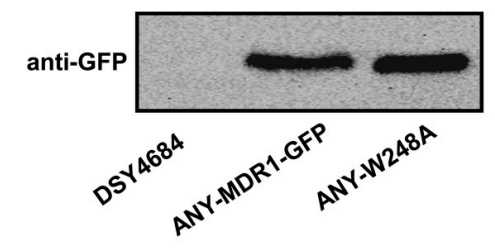

C

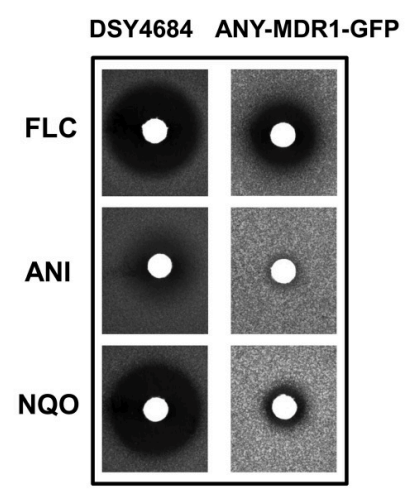

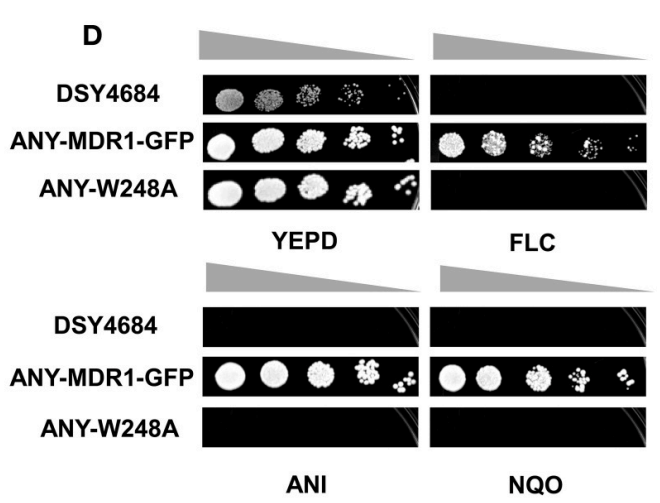

FIGURE 8 | The endogenous overexpression system for expression of a MFS superfamily protein. MDR1 with a C-terminal GFP tag was cloned into pDS1874 and overexpressed in DSY4684, the strain was designated as ANY-MDR1-GFP. (A) Confocal microscopy images of DSY4684, ANY-MDR1-GFP and its mutant. (B) Immunoblot analyses of their PM fractions (50 $\mu \mathrm{g}$ total protein) with anti-GFP monoclonal antibody. (C) Agar drug-diffusion assays of DSY4684 and ANY-MDR1-GFP cells. Susceptibility to the following xenobiotics were tested: Fluconazole (FLC; $10 \mu \mathrm{g}$ ), Anisomycin (ANI; $6 \mu \mathrm{g}$ ) and 4-nitroquinoline 1-oxide (NQO; 1 $\mu \mathrm{g})$. (D) Drug resistance profiles of DSY4684, ANY-MDR1-GFP and its mutant variant determined by serial dilution assays. For serial dilution assays, the following drugs were used: ANI $(4 \mu \mathrm{g} / \mathrm{ml})$, FLC $(4 \mu \mathrm{g} / \mathrm{ml})$ and NQO $(0.25 \mu \mathrm{g} / \mathrm{ml})$.

transporters. The deletion of major MDR pumps such as CDR1, $C D R 2$, and MDR1 made this strain amenable to expression of MDR variants. Stable integration and overexpression of a single gene copy under the control of a CDR 1 native promoter was made available. The expression plasmid integration can be performed by single site digestion (BglII) to enable integration into the genomic locus at the CDR1 promoter.

This new endogenous overexpression system was validated by overexpressing a GFP tagged version of Cdr1p. The time course of GFP fluorescence in C. albicans cells expressing the fusion protein revealed that the protein was being properly trafficked to the cell surface. Our confocal microscopy and immunoblot analyses results showed that cells which were grown up to 8 hours had almost all their GFP fluorescence within the PM with only negligible amounts of trapped intracellular fluorescence. The overexpressed Cdr1p was fully functional since DSY4687-5 (CDR1-GFP) had significantly higher resistance to all the tested drugs as compared with the susceptible control strain lacking the known MDR pumps (DSY4684).

To further explore the suitability of the C. albicans overexpression system, we recreated earlier three well characterized crucial TMH mutants of Cdr1p in the endogenous system (Rawal et al., 2013). Our assays showed that two of the three mutants, L529A and V532A, behaved similarly as was the case when overexpressed in S. cerevisiae. Interestingly, the C1294A mutant showed a few contrasting phenotypes. For instance, even though R6G and NR transport in C1294A cells was impaired, the cells continued to display resistance to all the other tested drugs. $\left[{ }^{3} \mathrm{H}\right]$ FLC accumulation assay further confirmed that the mutant variant was specifically defective in R6G and NR transport.

Considering that Cdrlp possesses multiple overlapping minibinding sites within the large binding cavity harboring common as well as specific residues for a particular substrate (Rawal et al., 2013), it is plausible that mutating C1294 to alanine might have specifically perturbed R6G and NR binding/transport. Contradictorily, it was not the case observed when the C1294A variant was overexpressed in S. cerevisiae as there it was found to be susceptible to all tested substrates.

The subtle differences in membrane environment between the two species could be responsible for this differential behavior of the mutant. Obviously, this aspect requires further investigation. Nevertheless, our results point toward distinctive behavior of membrane pump proteins when expressed in different environments.

The usefulness of this overexpression system for the identification and characterization of fungal pump inhibitors was evident from the fact that the calceneurin inhibitor FK520, which shows fungicidal synergism with azoles in the Cdr1p overexpressing S. cerevisiae system (Saini et al., 2005; Nim et al., 2014), also potentiated the growth inhibition of DSY4687-5 cells in the presence of FLC at much lower its MIC value. 
In order to extend the application of this newly developed system for the analyses of other classes of multidrug transporters, we overexpressed a protein belonging to the MFS superfamily. For this purpose, Mdrlp of C. albicans was integrated in DSY4684. We also constructed a variant $\left(\mathrm{Mdr}^{\mathrm{W} 248 \mathrm{~A}}\right)$ in the same background. Our results indicate that a non-ABC transport protein could also be functionally overexpressed in the PM of the host DSY4684. Expectedly, the cells overexpressing the $\mathrm{Mdr} 1^{\mathrm{W} 248 \mathrm{~A}}$ variant were susceptible to all tested drugs, which is consistent with earlier reports where W248 in TMH5 was identified as a crucial determinant of substrate recognition and transport in Mdr1p (Pasrija et al., 2007).

In conclusion, our results justifies the suitability and utility of this newly developed system for overexpression and functional characterization for a wide set of membrane proteins of $C$. albicans. Additionally, the lack of major endogenous MDR pumps and a TAC1 mediated constitutive membrane protein overexpression provides a powerful platform to identify novel substrates and chemosensitizers. The system can still be optimized with the deletion of other MDR genes to serve as a valuable tool for studies on fungal MDR pumps.

\section{AUTHOR CONTRIBUTIONS}

$\mathrm{RP}, \mathrm{DS}, \mathrm{AB}$, and NKK conceived and designed the experiments. $\mathrm{AB}$ and NKK performed the experiments. RP, DS, AB, and NKK analyzed the data. RP and DS contributed reagents and materials. $\mathrm{AB}, \mathrm{RP}$, and DS contributed to writing of the manuscript.

\section{REFERENCES}

Coste, A., Selmecki, A., Forche, A., Diogo, D., Bougnoux, M.-E., d’Enfert, C., et al. (2007). Genotypic evolution of azole resistance mechanisms in sequential Candida albicans isolates. Eukaryot. Cell 6, 1889-1904. doi: 10.1128/EC.00 151-07

Coste, A., Turner, V., Ischer, F., Morschhäuser, J., Forche, A., Selmecki, A., et al. (2006). A mutation in Taclp, a transcription factor regulating CDR1 and CDR2, is coupled with loss of heterozygosity at chromosome 5 to mediate antifungal resistance in Candida albicans. Genetics 172, 2139-2156. doi: 10.1534/genetics.105.054767

Hayama, K., Ishibashi, H., Ishijima, S. A., Niimi, K., Tansho, S., Ono, Y., et al. (2012). A D-octapeptide drug efflux pump inhibitor acts synergistically with azoles in a murine oral candidiasis infection model. FEMS Microbiol. Lett. 328, 130-137. doi: 10.1111/j.1574-6968.2011.02490.x

Kaur, R., and Bachhawat, A. K. (1999). The yeast multidrug resistance pump, Pdr5p, confers reduced drug resistance in erg mutants of Saccharomyces cerevisiae. Microbiology 145(Pt 4), 809-818. doi: 10.1099/13500872-145-4-809

Krishnamurthy, S. (1999). Membrane fluidity affects functions of Cdrlp, a multidrug ABC transporter of Candida albicans. FEMS Microbiol. Lett. 173, 475-481. doi: 10.1111/j.1574-6968.1999.tb13541.x

Lamping, E., Monk, B. C., Niimi, K., Holmes, A. R., Tsao, S., Tanabe, K., et al. (2007). Characterization of three classes of membrane proteins involved in fungal azole resistance by functional hyperexpression in Saccharomyces cerevisiae. Eukaryot. Cell 6, 1150-1165. doi: 10.1128/EC.00091-07

Maurya, I. K., Thota, C. K., Verma, S. D., Sharma, J., Rawal, M. K., Ravikumar, B., et al. (2013). Rationally designed transmembrane peptide mimics of the multidrug transporter protein Cdr1 act as antagonists to selectively block drug efflux and chemosensitize azole-resistant clinical isolates of Candida albicans. J. Biol. Chem. 288, 16775-16787. doi: 10.1074/jbc.M113.467159

\section{FUNDING}

Work is supported by a grant to RP from the Department of Biotechnology: DBT No.BT/01/CEIB/10/III/02. Financial Support from Indo-Swiss Research grant (ISJRP grant No. 122_917) to DS and RP, for supporting NK's visit to CHUV, Lausanne is acknowledged. DS is supported by a Swiss National Research Foundation grant 31003A_146936.

\section{ACKNOWLEDGMENTS}

The authors acknowledge Central Instrumentation Facility (CIF), SLS and Advanced Instrumentation and Research Facility (AIRF), JNU for Confocal microscopy facility. Authors are thankful to Ranbaxy Laboratories for the generous gift of fluconazole. The authors also thank F. Ischer for excellent technical assistance and M. Raymond (Montreal) for kind gift of strains. AB and NKK are thankful to Senior Research Fellowship Award from Council of Scientific and Industrial Research and University Grants Commission, India. Financial Support from Indo-Swiss Research grant (ISJRP grant No. 122_917) to DS and RP, for supporting NKK's visit to CHUV, Lausanne is acknowledged.

\section{SUPPLEMENTARY MATERIAL}

The Supplementary Material for this article can be found online at: http://journal.frontiersin.org/article/10.3389/fmicb. 2016.00261

Murad, A. M., Lee, P. R., Broadbent, I. D., Barelle, C. J., and Brown, A. J. (2000). CIp10, an efficient and convenient integrating vector for Candida albicans. Yeast 16, 325-327. doi: 10.1002/1097-0061(20000315)16:4<325::AIDYEA538>3.0.CO;2-\#

Niimi, K., Harding, D. R. K., Holmes, A. R., Lamping, E., Niimi, M., Tyndall, J. D. A., et al. (2012). Specific interactions between the Candida albicans ABC transporter Cdr1p ectodomain and a D-octapeptide derivative inhibitor. Mol. Microbiol. 85, 747-767. doi: 10.1111/j.1365-2958.2012.08140.x

Nim, S., Rawal, M. K., and Prasad, R. (2014). FK520 interacts with the discrete intrahelical amino acids of multidrug transporter Cdr1 protein and acts as antagonist to selectively chemosensitize azole-resistant clinical isolates of Candida albicans. FEMS Yeast Res. 14, 624-632. doi: 10.1111/1567-1364. 12149

Opekarová, M., and Tanner, W. (2003). Specific lipid requirements of membrane proteins-a putative bottleneck in heterologous expression. Biochim. Biophys. Acta 1610, 11-22. doi: 10.1016/S0005-2736(02)00708-3

Pasrija, R., Banerjee, D., and Prasad, R. (2007). Structure and function analysis of CaMdrlp, a major facilitator superfamily antifungal efflux transporter protein of Candida albicans: identification of amino acid residues critical for drug/H+ transport. Eukaryot. Cell 6, 443-453. doi: 10.1128/EC.00315-06

Pasrija, R., Panwar, S. L., and Prasad, R. (2008). Multidrug transporters CaCdrlp and CaMdrlp of Candida albicans display different lipid specificities: both ergosterol and sphingolipids are essential for targeting of CaCdrlp to membrane rafts. Antimicrob. Agents Chemother. 52, 694-704. doi: 10.1128/AAC.00861-07

Puri, N., Manoharlal, R., Sharma, M., Sanglard, D., and Prasad, R. (2011). Overcoming the heterologous bias: an in vivo functional analysis of multidrug efflux transporter, CgCdrlp in matched pair clinical isolates of Candida glabrata. Biochem. Biophys. Res. Commun. 404, 357-363. doi: 10.1016/j.bbrc.2010.11.123 
Puri, N., Prakash, O., Manoharlal, R., Sharma, M., Ghosh, I., and Prasad, R. (2010). Analysis of physico-chemical properties of substrates of ABC and MFS multidrug transporters of pathogenic Candida albicans. Eur. J. Med. Chem. 45, 4813-4826. doi: 10.1016/j.ejmech.2010.07.050

Rawal, M. K., Khan, M. F., Kapoor, K., Goyal, N., Sen, S., Saxena, A. K., et al. (2013). Insight into pleiotropic drug resistance ATP-binding cassette pump drug transport through mutagenesis of Cdr1p transmembrane domains. J. Biol. Chem. 288, 24480-24493. doi: 10.1074/jbc.M113.488353

Rogers, P. D., and Barker, K. S. (2003). Genome-wide expression profile analysis reveals coordinately regulated genes associated with stepwise acquisition of azole resistance in Candida albicans clinical isolates. Antimicrob. Agents Chemother. 47, 1220-1227. doi: 10.1128/AAC.47.4.12201227.2003

Rothnie, A., Theron, D., Soceneantu, L., Martin, C., Traikia, M., Berridge, G., et al. (2001). The importance of cholesterol in maintenance of P-glycoprotein activity and its membrane perturbing influence. Eur. Biophys. J. 30, 430-442. doi: $10.1007 /$ s002490100156

Saeki, T., Shimabuku, A. M., Azuma, Y., Shibano, Y., Komano, T., and Ueda, K. (1991). Expression of human P-glycoprotein in yeast cells-effects of membrane component sterols on the activity of P-glycoprotein. Agric. Biol. Chem. 55, 1859-1865. doi: 10.1271/bbb1961.55.1859

Saini, P., Prasad, T., Gaur, N. A., Shukla, S., Jha, S., Komath, S. S., et al. (2005). Alanine scanning of transmembrane helix 11 of Cdrlp ABC antifungal efflux pump of Candida albicans: identification of amino acid residues critical for drug efflux. J. Antimicrob. Chemother. 56, 77-86. doi: 10.1093/jac/ dki183

Sanglard, D., Ischer, F., Monod, M., and Bille, J. (1996). Susceptibilities of Candida albicans multidrug transporter mutants to various antifungal agents and other metabolic inhibitors. Antimicrob. Agents Chemother. 40, 2300-2305.

Sanglard, D., and Odds, F. C. (2002). Resistance of Candida species to antifungal agents: molecular mechanisms and clinical consequences. Lancet. Infect. Dis. 2, 73-85. doi: 10.1016/S1473-3099(02)00181-0

Santos, M. A., and Tuite, M. F. (1995). The CUG codon is decoded in vivo as serine and not leucine in Candida albicans. Nucleic Acids Res. 23, 1481-1486. doi: 10.1093/nar/23.9.1481

Shah, A. H., Banerjee, A., Rawal, M. K., Saxena, A. K., Mondal, A. K., and Prasad, R. (2015a). ABC transporter Cdrlp harbors charged residues in the intracellular loop and nucleotide-binding domain critical for protein trafficking and drug resistance. FEMS Yeast Res. 15:fov036. doi: 10.1093/femsyr/ fov036

Shah, A. H., Rawal, M. K., Dhamgaye, S., Komath, S. S., Saxena, A. K., and Prasad, R. (2015b). Mutational analysis of intracellular loops identify cross talk with nucleotide binding domains of yeast ABC transporter Cdr1p. Sci. Rep. 5:11211. doi: $10.1038 /$ srep 11211

Sharom, F. J. (1997). The P-glycoprotein multidrug transporter: interactions with membrane lipids, and their modulation of activity. Biochem. Soc. Trans. 25 , 1088-1096. doi: 10.1042/bst0251088

Shukla, S., Saini, P., Smriti, Jha, S., Ambudkar, S. V., and Prasad, R. (2003). Functional characterization of Candida albicans ABC transporter Cdr1p. Eukaryot. Cell 2, 1361-1375. doi: 10.1128/EC.2.6.1361-1375.2003

Staib, P., Kretschmar, M., Nichterlein, T., Hof, H., and Morschhäuser, J. (2000). Differential activation of a Candida albicans virulence gene family during infection. Proc. Natl. Acad. Sci. U.S.A. 97, 6102-6107. doi: $10.1073 /$ pnas. 110031497

Tsao, S., Rahkhoodaee, F., and Raymond, M. (2009). Relative contributions of the Candida albicans ABC transporters Cdr1p and Cdr2p to clinical azole resistance. Antimicrob. Agents Chemother. 53, 1344-1352. doi: 10.1128/AAC.00926-08

Urbatsch, I. L., and Senior, A. E. (1995). Effects of lipids on ATPase activity of purified Chinese hamster P-glycoprotein. Arch. Biochem. Biophys. 316, 135-140. doi: 10.1006/abbi.1995.1020

White, T. C. (1997). Increased mRNA levels of ERG16, CDR, and MDR1 correlate, with increases in azole resistance in Candida albicans isolates from a patient infected with human immunodeficiency virus. Antimicrob. Agents Chemother. $41,1482-1487$

White, T. C., Marr, K. A., and Bowden, R. A. (1998). Clinical, cellular, and molecular factors that contribute to antifungal drug resistance. Clin. Microbiol. Rev. 11, 382-402.

Znaidi, S., De Deken, X., Weber, S., Rigby, T., Nantel, A., and Raymond, M. (2007). The zinc cluster transcription factor Taclp regulates PDR16 expression in Candida albicans. Mol. Microbiol. 66, 440-452. doi: 10.1111/j.13652958.2007.05931.x

Conflict of Interest Statement: The authors declare that the research was conducted in the absence of any commercial or financial relationships that could be construed as a potential conflict of interest.

Copyright (c) 2016 Banerjee, Khandelwal, Sanglard and Prasad. This is an openaccess article distributed under the terms of the Creative Commons Attribution License (CC BY). The use, distribution or reproduction in other forums is permitted, provided the original author(s) or licensor are credited and that the original publication in this journal is cited, in accordance with accepted academic practice. No use, distribution or reproduction is permitted which does not comply with these terms. 